\title{
Teaching teamwork: an evaluation of an interprofessional training ward placement for health care students
}

This article was published in the following Dove Press journal:

Advances in Medical Education and Practice

25 June 2014

Number of times this article has been viewed

\section{Julia Morphet' \\ Kerry Hood ${ }^{2}$ \\ Robyn Cant ${ }^{2}$ \\ Julie Baulch ${ }^{3}$ \\ Alana Gilbee ${ }^{3}$ \\ Kate Sandry ${ }^{4}$}

'School of Nursing and Midwifery, Monash University, Frankston, Victoria, Australia; ${ }^{2}$ School of Nursing and Midwifery, Monash University, Clayton, Victoria, Australia; ${ }^{3}$ Southern Clinical School, Monash University, Monash Health, Clayton, Victoria, Australia; ${ }^{4}$ Dandenong Emergency Department, Monash Health, David St, Dandenong, Victoria, Australia
Correspondence: Robyn Cant School of Nursing and Midwifery, Monash University, Berwick, Victoria, Australia, 3806

Tel +6I 438363634

Email robyn.cant@monash.edu

\begin{abstract}
The establishment of interprofessional teamwork training in the preprofessional health care curriculum is a major challenge for teaching faculties. Interprofessional clinical placements offer an opportunity for teamwork education, as students in various professions can work and learn together. In this sequential, mixed-method study, focus group and survey techniques were used to evaluate students' educational experiences after 2-week ward-based interprofessional clinical placements. Forty-five senior nursing, medicine, and other health care students cared for patients in hospital wards under professional supervision, with nursingmedicine student "teams" leading care. Thirty-six students attended nine exit focus groups. Five central themes that emerged about training were student autonomy and workload, understanding of other professional roles, communication and shared knowledge, interprofessional teamwork/ collaboration, and the "inner circle", or being part of the unit team. The learning environment was described as positive. In a postplacement satisfaction survey $(n=38)$, students likewise rated the educational experience highly. In practicing teamwork and collaboration, students were able to rehearse their future professional role. We suggest that interprofessional clinical placements be regarded as an essential learning experience for senior preprofessional students. More work is needed to fully understand the effect of this interactive program on students' clinical learning and preparation for practice.
\end{abstract}

Keywords: education, medical, undergraduate, experiential learning, interprofessional learning, nursing, teamwork

\section{Introduction}

Teamwork and collaboration among health care professionals have become increasingly important because of changing health care systems, both in and out of hospital, in primary care. ${ }^{1}$ Traditional, hierarchical models of care have given way to partnerships and "community" approaches. ${ }^{2,3}$ Patients who once remained in hospital now move through various levels of health care, assisted by a diverse group (or "team") of clinicians who regularly communicate with each other about the care of a defined group of patients and who participate in that care. ${ }^{4}$ The transitions require planning and communication among professionals and communication with the patients and their family members. Furthermore, patients' outcomes have been shown to improve with team-based care. ${ }^{5}$ These issues affect the curricula of preregistration health care courses as they educate a new generation of professionals.

Universities are required to do more than graduate clinically competent practitioners: Graduates also should be skilled in collaborating with members of the multidisciplinary care team. Nurses and other professionals can contribute clinical and 
behavioral skills and balance the elements of care that doctors may neither be trained for nor have time to do. ${ }^{4}$ In line with a worldwide movement, ${ }^{6}$ both the nursing and medical professions in Australia mandate that students be prepared for collaborative practice, ${ }^{7,8}$ although there is little evidence of interprofessional education to date. ${ }^{9}$ Addressing this objective, this article reports an evaluation of a preregistration interprofessional education program that aimed to enhance the skills of medical and nursing students to prepare them for real-world practice.

It has been reported that future collaboration can be enhanced by giving students in various professions opportunities to learn together. ${ }^{10}$ True interprofessional learning requires student interactions: active learning among disciplines when two or more students learn with, from, and about each other in shared exchanges. ${ }^{11}$ The ideal interprofessional clinical learning experience, however, involves students from several disciplines in experiential learning in practice-based settings. ${ }^{9}$

One such learning environment is a "training ward", in which preregistration health care students work in interprofessional teams, while under supervision, to manage the care of patients. Successful training ward programs have included orthopedic wards in Scandinavia and the United Kingdom, ${ }^{12-15}$ a stroke and acute medical unit in Canada, ${ }^{16}$ and a medical ward in Western Australia. ${ }^{17}$ These settings engage students in interprofessional patient care and provide learning experiences at a level of difficulty manageable for undergraduate students. Training ward studies in Scandinavia have reported multiple positive student and patient outcomes. ${ }^{13,14,18-20}$ The students' confidence, competence, and understanding of the importance of communication and teamwork related to patient care were improved, along with understanding of their own professional role and the role of other professions.

This article aims to describe the effect on students of learning during interprofessional clinical placements (ICPs) in two training wards in Melbourne, Australia. Final-year preprofessional students in nursing and in medicine led the care of selected patients in a large metropolitan health service emergency department and a rehabilitation (restorative) ward. The study formed one phase of a project trialing clinical education opportunities for health care students, ${ }^{21}$ in which we had identified that students were initially positive about the concept of interprofessional education. We describe the ICP program and report on the perceived effect on learning teamwork reported by participating students.

\section{Methods}

A sequential, qualitative-quantitative, mixed-methods evaluation of the ICP program was undertaken using focus group and survey techniques. All students who participated in the ICPs were invited to attend an end-of-placement focus group discussion (nine focus groups were held in total) and to complete a satisfaction survey. Feedback from clinical teachers was gathered in separate end-of-program interviews.

\section{Participants and clinical care procedures}

Student volunteers undertook the trial placements according to their availability. Ten rounds of 2-week placements were conducted in two wards between May and October 2012, with 45 students. During day shifts, two student teams of one fifth-year medical and one third-year nursing student (NS) were responsible for managing patients in two dedicated ward beds in each setting. Supervision was provided by clinical educator facilitators from each discipline who were trained in interprofessional teaching.

Student teams worked to assess patients and to plan and manage care, including investigations, referral, and discharge. At the end of each shift, teams handed over to ward staff, and facilitators usually held a student debriefing. In the emergency department, teams were supervised by an emergency department-experienced registered nurse and a senior medical registrar or emergency physician. Ten medical students (MSs) and ten NSs participated. In the rehabilitation ward, the core medicine-nursing student teams were assisted by other preprofessional students where advisable and when available. A total of ten MSs, eight NSs, and seven other students (nutrition/dietetics, social work, pharmacy, occupational therapy) participated. One registered nurse $(\mathrm{RN})$ facilitator oversaw the students' patient management, together with the usual ward staffing (eg, other nurses, visiting physicians). Students participated in medical rounds and unit meetings. Formal feedback was provided to students in each setting through debriefing and a case presentation.

\section{Evaluation}

On the last day of each placement (day 10), feedback was sought from students via focus group and questionnaire. All students were invited to complete a satisfaction survey, the Interprofessional Clinical Placement Learning Environment Inventory (ICPLEI). This scale (Table 1) included 26 items rated from 1 (strongly disagree) to 5 (strongly agree). It explored student perceptions of the learning environment, including orientation, supervision, roles, learning, communication, and autonomy. When administered to the students, the 
Table I Participants' feedback: Interprofessional Clinical Placement Learning Environment Inventory $(n=38)$

\begin{tabular}{|c|c|c|}
\hline Item & $\begin{array}{l}\text { Mean } \\
\text { score }\end{array}$ & $\begin{array}{l}\text { Standard } \\
\text { deviation }\end{array}$ \\
\hline I. The purpose (learning objectives) of this placement was made clear. & 4.32 & 0.73 \\
\hline 2. I needed more orientation to this placement.* & $4.24(\mathrm{R})$ & 0.74 \\
\hline 3. Orientation was relevant and well-organized. & 4.26 & 0.62 \\
\hline 4. The teaching strategies helped my learning. & 4.11 & 0.73 \\
\hline 5. My preference is for teachers to be of the same discipline as the student. & 2.82 & 1.14 \\
\hline 6. I valued having more than my own discipline being involved in teaching. & 4.47 & 0.66 \\
\hline 7. There was too much supervision on this placement.* & $3.82(\mathrm{R})$ & 0.83 \\
\hline 8. This clinical placement was interesting. & 4.52 & 0.49 \\
\hline 9. The workload was too heavy.* & $4.21(\mathrm{R})$ & 0.41 \\
\hline 10. There was too much pressure on me in this placement.* & $4.18(\mathrm{R})$ & 0.83 \\
\hline II. This clinical placement was well-organized. & 4.32 & 0.54 \\
\hline 12. I usually had a clear idea of what was expected of me. & 4.00 & 0.85 \\
\hline 13. I achieved the discipline specific learning objectives set by my university. & 3.82 & 0.71 \\
\hline 14. My other student commitments didn't interfere with my involvement in this placement. & 3.50 & 1.10 \\
\hline 15. The placement provided me with sufficient clinical learning opportunities. & 4.32 & 0.64 \\
\hline 16. I felt as if I belonged to the ward. & 4.62 & 0.49 \\
\hline 17. The teachers were friendly and approachable. & 4.65 & 0.49 \\
\hline 18. This placement has given me new insights in how a ward is run and managed. & 4.18 & 0.90 \\
\hline 19. After this placement, I understand more fully my discipline's role in the interprofessional clinical team. & 4.09 & 0.99 \\
\hline $\begin{array}{l}\text { 20. After this placement, I have a greater understanding of the role and function of other disciplines } \\
\text { in health care delivery. }\end{array}$ & 4.35 & 0.92 \\
\hline 21. I felt comfortable in asking for advice or assistance when necessary from my student colleagues. & 4.62 & 0.55 \\
\hline 22. I felt uncomfortable taking a lead in a student group.* & $3.35(\mathrm{R})$ & 1.37 \\
\hline 23. I felt uncomfortable sharing responsibility for delivery of health care.* & $3.85(\mathrm{R})$ & 1.28 \\
\hline 24. I felt comfortable putting forward my personal opinions in a group. & 4.35 & 0.81 \\
\hline 25. After this placement, I have a better understanding of the patient's role in health care decision making. & 3.88 & 1.07 \\
\hline 26. I felt comfortable communicating with patients and families to seek their input into care. & 4.41 & 0.50 \\
\hline
\end{tabular}

Notes: Scores are based on scores of I (strongly disagree) to 5 (strongly agree); includes mixed student disciplines. *Questions with a negative question stem were reversecoded to achieve average scores and marked with "(R)".

scale showed adequate internal consistency, with a Cronbach alpha of 0.75 (exceeding an expected 0.70 ). ${ }^{22}$

All students in each placement were invited to attend a focus group discussion aimed at obtaining more indepth views about the program. Audio-recorded group discussions were facilitated by a trained nurse-researcher and lasted between 20-45 minutes. An interview schedule was used to facilitate discussion, asking about the interprofessional learning (IPL) experience, including role clarification, team functioning and collaboration, interprofessional communication, person-centered care, and lessons learned.

\section{Analysis}

Quantitative survey data were entered into a database, IBMSPSS Statistics version 20 (IBM Corporation, Armonk, NY, USA). Following the ICPLEI analysis guide, six negative question items were recoded so that all scores indicated agreement when at the high end of the response scale $(4 ; 5)$. Results were reported using descriptive statistics (mean, median, percentage, standard deviation).
The focus group narratives were transcribed by an independent facility, and two nurse researchers separately analyzed the data, using inductive content analysis. Both researchers were independent of student supervision. Analysis involved each researcher in reading and rereading the transcripts and making coding and theme notes beside the transcribed data to ensure themes and subthemes were derived inductively from the raw data. ${ }^{23,24}$ Once each researcher had determined the emergent themes, findings were shared and the data underwent further collaborative refinement until consensus was achieved and the final themes and their nomenclature were agreed on.

Ethical approval was obtained for conduct of the study from both the health care network and the university.

\section{Results ICPLEl survey results}

The ICPLEI was completed by 38 students (17 MSs, 17 NSs, and four other health and social care students [OHs]; $85 \%$ of medical/nursing students). The average total score was 108 (standard deviation, 8.52) of a possible 130, with median 
ratings of 4 or 5 for all but one item, indicating overall positive responses (agreement). Students were ambivalent about the issue of whether teachers should be of the same discipline as the student, with a median "uncertain" score of three. Students viewed interprofessional placements as beneficial for their learning (see Table 1). No questions resulted in overall negative feedback.

Almost all students approved of the teaching, agreeing, "This clinical placement was interesting", "I valued having more than my own discipline being involved in teaching", "The placement provided me with sufficient clinical learning opportunities", and "I felt as if I belonged to the ward". Most students $(>80 \%)$ agreed or agreed strongly that they developed better role clarity. They also felt comfortable with their communication skills, both with student colleagues and with patients and families. An Independent Samples Kruskal-Wallis test showed there was no significant difference in overall scores between the nursing and medical student groups.

\section{Focus group findings}

Emergency department (ED) and rehabilitation ward participants $(n=36)$ attended one of nine focus groups (16 NSs, $16 \mathrm{MSs}$, and $4 \mathrm{OHs}$ ). Five main themes emerged: student autonomy and workload, understanding of other professional roles, communication and shared knowledge, interprofessional teamwork/collaboration, and the "inner circle", or being part of the unit team.

Overall, MSs, NSs, and OHs spoke very positively about their experiences during the ward ICP. "It's like an ideal world, having everyone work together, and it just got better and better... working as a team, being able to ask questions... . It's made it such a fun experience" (NS; Rehab FG1 [rehabilitation focus group 1]).

\section{Student autonomy and workload}

Many students felt an increased sense of autonomy and responsibility in the training ward ICP compared with in traditional clinical placements. NSs, who in traditional placements worked with a nurse preceptor on allocated tasks, felt more independent in the way they now managed the overall care of a patient and their patient load: "It was good to be actually able to do it ourselves and then go back and report to [the facilitator], rather than having her stand behind us while we do everything" (NS; ED FG2); "I felt that I could take control and they were my patients" (NS; ED FG4).

Other health and social care participants (OHs) agreed: "It has really taught me to manage my workload, not in isolation, but as part of the whole clinical experience" $(\mathrm{OH}$; Rehab FG1). This sense of independence was supported by MSs, who, despite having worked with some degree of autonomy in preceding weeks, reported, "I have been in [emergency department] for 3 weeks, and on the [interprofessional] placement, I felt more efficient in looking after the patient" (MS; ED FG3).

Students' views differed regarding an ideal patient workload. MSs were divided on the issue of work volume, with some feeling they had less patient responsibility than usual and could have managed more. However, there were unexpected learnings: "This was a lot more relaxed for us (laughs). Well, it's a positive from the perspective of learning all these things that I didn't know about, learning practical skills that nurses do, that I don't know how to do" (MS; ED FG2); "I wasn't bored. The more you knew the patient, the more there was to do" (MS; Rehab FG1).

\section{Understanding of other professional roles}

Students across disciplines thought that developing a better understanding of one another's professional roles was one of the most beneficial outcomes. Students often had only experienced learning with their professional group. As an MS stated, "I've [...] been [...] on clinical placements for about 2 years. [I've] never really worked with nurses" (medical student [MS] 2; Rehab FG1).

MSs also reported greater respect for nurses' roles: "I have a better understanding of the role of nurses. Like, probably before, it would be just of getting urine samples, fecal samples (laughs) and obs [observations] for the patient. But now I understand how they prioritize their tasks. Before, I would have no idea how any of that worked" (MS1); "It is so valuable for us to be aware of, going into, you know, our internship [next year]. We should be knowing what the nurses do, you know?" (MS2; ED FG1).

Students described understanding the roles of others as being important learning related to future practice because the workload could then be shared. An improved understanding of roles and role boundaries was enabled through "doing". This learning emerged from managing serial patient admissions over 2 weeks with repeated practice of care planning and initiating and managing treatment. "We learnt more about [our] own roles by being able to discuss with each other what we were going to do with the patient: Who was going to do what with them" (NS, Rehab FG4).

NSs found doctors' roles more detailed than previously supposed, and OHs felt more confident knowing "what was going on". A pharmacy student found the ward experience 
enabled a more holistic view of patient care: "Normally we don't get to see what the allied health really does, and in this program we can see, like, what OT [occupational therapy] does... . Well, I guess it kind of makes you think about the broad picture of the patient" (OH; Rehab FG1).

MSs summarized this improvement in role clarity and the benefits, saying, "It gives you an idea of what exactly the other team members' jobs involve. And sort of, when you [should] call on them, you know? And how you can help them and how they can help you" (MS2). It was apparent that students in the emergency department had less experience interacting with $\mathrm{OHs}$ than those in the rehabilitation ward. It appeared, however, that all students perceived the ICP experience as providing highly beneficial lessons with regard to increased practical knowledge of professionals' roles and role boundaries.

\section{Communication and shared knowledge}

Students reported that knowing the members of the ICP team in person and working in a shared space over an extended period allowed them to feel more comfortable communicating directly with one another. The interprofessional placement model encouraged sharing of patient information. "Getting together every day to discuss the patients' goals and their progress, there are no miscommunications" (NS; Rehab FG1).

Although familiarity might have led to increased frequency and content of communication, there was also a developing expectation of multiple contributions from others. "Yes, we're all busy, but everyone is approachable. As a doctor, I want to be open to input from other health professionals" (MS; Rehab FG1).

Students felt more comfortable asking questions of those in other disciplines, especially when this might reveal a gap in knowledge. Previously, when they lacked knowledge and were seeking information, they might have "searched on the computer" (NS; Rehab FG5). Now, however, "If the medical team was out of their depth with regard to medications and doses, then you would just ask the pharmacist. [It's] automatic" (MS; Rehab FG5). One student acknowledged this collaboration and the benefit of team input: "There are deficits of knowledge in everyone's [skill set] that someone else fills in" (NS; Rehab FG1).

\section{Interprofessional teamwork/collaboration}

Students practiced a team approach: "I think it is a great opportunity to work as a team, and especially when you're so close to what will be expected next year of us" (MS; Rehab FG4).
The students tried to undertake patient assessments together, especially as this prevented a patient from having to explain things twice. After assessing a patient, students would discuss their findings and come to an agreement about management. "We would usually do assessments together and then come out and say, 'Okay, we need an MSU [mid stream urine] or bloods', or he'd ask me if there was anything else I thought they needed, and I'd ask him questions or prompt him" (NS; ED FG4).

Students believed good communication and collaborative decision-making were a strength of teamwork, which was believed to help prevent time delays, and even to improve overall management. As stated earlier, there were "no miscommunications", and patient referrals could be made and actions taken promptly.

Students also felt they had learned much through observing the others: "I have benefited from seeing how the medical students extract information from patients" (NS; ED FG3). Other students reported that collaboration helped them to think about the bigger picture for the patient, including how the patient will manage at home, and not simply whether they were medically cleared for discharge.

Overall, it was apparent from student descriptions that there was collaborative working. Students developed independence and were able to put forward their views in mixed groups. They viewed the practice of collaborative working with their colleagues very positively as a preparation for their future work.

\section{The inner circle: being part of the unit team}

Students in both wards reported that being part of a studentled team helped them "fit in" to the larger unit professional team. Unit staff recognized the student team, and students were included in patient management discussions, which was an unfamiliar experience for both NSs and MSs. For a medical student, "this was the first time in my medical student life that I felt like I was an active member of a team" (MS; Rehab FG1). "It was good to work in a team with a nursing student. That way, like, certain tasks could be delegated between us. That was really helpful" (MS; ED FG4).

MSs reported uniprofessional working as being more usual in the emergency department. An NS explained this new and elevated team-based role in the rehabilitation ward: "Normally, in a ward round, they shut the curtain on you ... but with this, because we were the team, everyone was on board. All the doctors, all the consultants, everyone knew that we were going around as a team. And therefore, we 
were allowed inside the curtain, in that inner circle" (NS3; Rehab FG1).

This explanation refers to discussions about patient care plans that were held at the bedside among the patient, nursing staff, and medical team members, who were all clustered around the patient's bed behind a curtain. A sense of inclusion allowed students to place a positive value on their own contribution and thus develop confidence for future teamwork. "I'm not expecting that the consultants are going to be asking me anything next time. But I do have more confidence in knowing that I'm an expert in my area. And therefore [I] have a right to speak up" (OH; Rehab FG1). Thus, the interprofessional placement model appeared to meet student needs for learning on a number of levels and was strongly applauded by student participants.

\section{Substantiation of results}

Although qualitative inquiry using focus groups can be prone to bias, we determined the trustworthiness of the results by comparing the findings between various data sourced from the same study. We explored methodological triangulation ${ }^{25}$ by comparing the themes from focus groups with students' ICPLEI responses. Both sources of data provided positive responses about teaching, role clarity, collaboration and communication, and the general effect of the placement. Investigator triangulation was achieved through results review. ${ }^{26}$ Three nurse-researchers read the actual focus group narratives, and the resulting coding and themes to confirm the key findings were applicable and in agreement. Data triangulation was achieved by comparing several types of data sources. We compared the qualitative focus group and quantitative survey results described earlier with themes from four clinical teacher interviews or focus groups $(n=9$ staff), facilitators' field notes, and a patient satisfaction survey of 102 patients who were managed by students in the emergency department. We found agreement throughout, regarding perceptions of a positive effect on students who were learning their professional function through training ward experiences.

\section{Discussion}

Teamwork has received little attention in the medical curriculum, ${ }^{27}$ even though education is required for individuals to function within a team ${ }^{28}$ and patient safety is improved with team-based management. ${ }^{5}$ Teamwork has been defined as behaviors that facilitate effective team member interaction, requiring appropriate knowledge, skills, and attitudes in professionals. ${ }^{29}$ Teamwork knowledge involves an understanding of the roles and responsibilities of team members and of the team's mission; teamwork skills refer to the learned capacity to perform a task, such as communicating clearly and effectively. ${ }^{29}$ In addition, teamwork attitudes reveal mental attitudes that can affect behaviors and that show the value an individual places on working in a team. ${ }^{30}$ Thus, to perform as a member of a multidisciplinary team, students need to be capable of a number of dynamic interactions.

Students were highly satisfied with the teaching and learning opportunities in this interprofessional placement, describing improved teamwork and collaborative skills. They described gaining a better understanding of professional roles, knowledge of role boundaries, working collaboratively, becoming practiced at communicating with other disciplines, and gaining confidence to ask for assistance. In addition, they achieved a priority objective: being accepted into the clinical team as a "professional" in the inner circle on mastery of independent practice. The placement model provided them with opportunities to learn in a secure atmosphere through observation, by "doing", and through team interactions and from feedback. In general, there appeared to be largely productive and positive effects on students from this model of interactive learning.

The findings align with prior studies describing interprofessional clinical learning in training wards as positive, with benefits to learning. ${ }^{13,14,19,20}$ The training of MSs, NSs, and physiotherapy students in a 2 -week IPL ward placement in Sweden reported significantly increased knowledge of the students' own professional roles and that of others. ${ }^{13}$ In another similar study of training ward placements, students from medicine, nursing, occupational therapy, and physiotherapy ( $n=982$ ) perceived the ward as a good-quality training environment and were able to develop their own professional roles and their function as a team member. ${ }^{20}$

Internationally, however, there is a lack of consensus about the key learning outcomes for interprofessional clinical education. Our findings concur with five of the six main learning outcomes that were suggested by Thistlethwaite and Moran ${ }^{10}$ for interprofessional education. The related themes suggested were teamwork, roles/responsibilities, communication, learning and reflection, and the patient. This lack of clarity in outcomes of interprofessional education may have affected curriculum planning, for despite commitment, the teaching of teamwork in preregistration programs appears limited. Logistical and timetabling barriers to interprofessional education limit the ability to situate students in the same place at the same time to learn together. ${ }^{10}$ A survey of Australian and New Zealand universities showed that around one quarter of nursing and 
medicine courses had included any interprofessional education in their curriculum. ${ }^{9}$ In contrast, a survey of nursing and medicine programs in Norway found that most in medicine had developed interprofessional teamwork education in their clinical training, and nursing programs offered theory-based classroom education regarding teamwork..$^{31}$

In Australia, competency standards for entry into practice as a registered nurse prescribe nurses' communication and collaboration with the interdisciplinary health care team. ${ }^{7}$ Furthermore, communication and team leadership are two of five competencies in the Australian Curriculum Framework for junior doctors after their internship. ${ }^{32}$ In the United States, eight medical schools developed curricula to teach teamwork and leadership, with most designs using clinical teams in the clinical rotations to achieve learning objectives. ${ }^{27}$ There is a need to expand on these programs to offer interprofessional clinical training, such as in this program more widely, to facilitate the development of teamwork competence in nursing, medical, and other health and social care education.

Some limitations of this study are recognized. A small sample of 38 students who were on clinical placement during the same period may not be representative of all professions. The number of participants in each focus group was small and comprised multiple disciplines, perhaps limiting discussion because of social desirability. Selection of a convenience sample of students for the ICP program may have biased results, and less confident students may have performed differently. Furthermore, all students were from a single university. As with all qualitative research, the interpretation of results can be subject to bias. Efforts were made, however, to systematically apply the tenets of a mixed-methods design to enable exploration of the learning experiences and to accurately represent students' voices. This descriptive study can therefore offer insights into the effect of a ward-based interprofessional clinical placement on students' learning.

\section{Conclusion}

The establishment of interprofessional teamwork training in the health care curriculum is a major challenge for the clinical education community. ICPs offer an opportunity to address teamwork education. Experiential learning provides a place for preprofessional students to work together in authentic ways before assuming their professional roles. Senior preprofessional health care students who experienced a 2-week, ward-based ICP reported beneficial learning outcomes. These included a better understanding of professional roles, collaboration, communication, and teamwork: They rehearsed their future role.
Such interactive learning experiences offer students a glimpse of their professional futures and should be regarded as an essential learning experience for senior students. More work is needed to fully understand the effect of this interactive program on students' clinical learning and their preparation for practice.

\section{Disclosure}

The authors report no conflicts of interest in this work.

\section{References}

1. Frenk J, Chen L, Bhutta ZA, et al. Health professionals for a new century: transforming education to strengthen health systems in an interdependent world. Lancet. 2010;376(9756):1923-1958.

2. Adler P, Kwon S, Anderson A, Heckscher C. Professional work: the emergence of collaborative community. Organization Sc. 2008;19(2): 359-376.

3. Baker MJ, Durham CF. Interprofessional education: a survey of students' collaborative competency outcomes. J Nurs Educ. 2013; 52(12):713-718.

4. Wagner EH. The role of patient care teams in chronic disease management. BMJ. 2000;320(7234):569-572.

5. Agency for Healthcare Research and Quality. TeamStepps: National Implementation. Rockville, MD: US Department of Health and Human Services; 2009. Available from: http://teamstepps.ahrq.gov/. Accessed: April 8, 2011.

6. World Health Organization, Health Professions Network Nursing and Midwifery Office. Framework for Action on Interprofessional Education and Collaborative Practice (WHO/HRH/HPN/10.3). Available from: http://www.who.int/hrh/resources/framework_action/en/. Geneva: World Health Organization; 2010. Accessed: January 8, 2014.

7. Nursing and Midwifery Board of Australia. National Competency Standards for the Registered Nurse. Melbourne, Australia: Nursing and Midwifery Board of Australia. Available from: http://www. nursingmidwiferyboard.gov.au/documents/default.aspx?record=WD $10 \% 2 \mathrm{~F} 1342 \& \mathrm{dbid}=\mathrm{AP} \&$ chksum $=\mathrm{N} 5 \mathrm{ws} 04 \mathrm{xdBlZijTTSdKnSTQ} \% 3 \mathrm{D}$ \%3D. Accessed: July 17, 2013.

8. Australian Medical Council. Assessment and Accreditation for Medical Schools: Standards and Procedure. Canberra, Australia: Australian Medical Council; 2010. Available from: http://www.amc.org.au/images/ Medschool/standards.pdf. Accessed: January 8, 2014.

9. Lapkin S, Levett-Jones T, Gilligan C. A cross-sectional survey examining the extent to which interprofessional education is used to teach nursing, pharmacy and medical students in Australian and New Zealand universities. J Interprof Care. 2012;26(5):390-396.

10. Thistlethwaite J, Moran M; World Health Organization Study Group on Interprofessional Education and Collaborative Practice. Learning outcomes for interprofessional education (IPE): Literature review and synthesis. J Interprof Care. 2010;24(5):503-513.

11. Centre for the Advancement of Interprofessional Education. Interprofessional education - a definition. CAIPE Bull. 1997;13:19.

12. Freeth D, Reeves S, Goreham C, Parker P, Haynes S, Pearson S. 'Real life' clinical learning on an interprofessional training ward. Nurse Educ Today. 2001;21(5):366-372.

13. Ericson A, Masiello I, Bolinder G. Interprofessional clinical training for undergraduate students in an emergency department setting. J Interprof Care. 2012;26(4):319-325.

14. Lindblom P, Scheja M, Torell E, Astrand P, Felländer-Tsai L. Learning orthopaedics: assessing medical students' experiences of interprofessional training in an orthopaedic clinical education ward. $J$ Interprof Care. 2007;21(4):413-423. 
15. Jacobsen F, Fink AM, Marcussen V, Larsen K, Hansen TB. Interprofessional undergraduate clinical learning: results from a three year project in a Danish Interprofessional Training Unit. $J$ Interprof Care. 2009;23(1):30-40.

16. Sommerfeldt SC, Barton SS, Stayko P, Patterson SK, Pimlott J. Creating interprofessional clinical learning units: developing an acute-care model. Nurse Educ Pract. 2011;11(4):273-277.

17. Faculty of Health Sciences Curtin University. 2012 Annual Report: Interprofessional Education. Perth, Australia: Curtin University; 2013. Available from: http://healthsciences.curtin.edu.au/local/docs/ IPE_Annual_Report_2012.pdf. Accessed: January 8, 2014.

18. Hallin K, Kiessling A, Waldner A, Henriksson P. Active interprofessional education in a patient based setting increases perceived collaborative and professional competence. Med Teach. 2009;31(2): 151-157.

19. Hylin U, Nyholm H, Mattiasson AC, Ponzer S. Interprofessional training in clinical practice on a training ward for healthcare students: a two-year follow-up. J Interprof Care. 2007;21(3):277-288.

20. Ponzer S, Hylin U, Kusoffsky A, et al. Interprofessional training in the context of clinical practice: goals and students' perceptions on clinical education wards. Med Educ. 2004;38(7):727-736.

21. Parsell G, Bligh J. Educational principles underpinning successful shared learning. Med Teacher. 1998;20:522-529.

22. Pallant JF. SPSS Survival Manual; A Step by Step Guide to Data Analysis Using SPSS. 2nd ed. Sydney: Allen \& Unwin; 2005.

23. Elo S, Kyngäs $\mathrm{H}$. The qualitative content analysis process. J Adv Nurs. 2008;62(1):107-115.

24. Moretti F, van Vliet L, Bensing J, et al. A standardized approach to qualitative content analysis of focus group discussions from different countries. Patient Educ Couns. 2011;82(3):420-428.
25. Denzin NK, Lincoln YS. The discipline and practice of qualitative research. In: Denzin NK, Lincoln YS, editors. Handbook of Qualitative Research. 2nd ed. Thousand Oaks, CA: Sage Publications; 2000:1-28.

26. Silverman D. Interpreting Qualitative Data; Methods for Analysing Talk, Text and Interaction. Thousand Oaks, CA: Sage Publications; 2001.

27. O'Connell MT, Pascoe JM. Undergraduate medical education for the 21st century: leadership and teamwork. Fam Med. 2004; 36 Suppl:S51-S56.

28. Hall P, Weaver L. Interdisciplinary education and teamwork: a long and winding road. Med Educ. 2001;35(9):867-875.

29. Beaubien JM, Baker DP. The use of simulation for training teamwork skills in health care: how low can you go? Qual Saf Health Care. 2004; 13 Suppl 1:i51-i56.

30. Baker DP, Amodeo AM, Krokos KJ, Slonim A, Herrera H. Assessing teamwork attitudes in healthcare: development of the TeamSTEPPS teamwork attitudes questionnaire. Qual Saf Health Care. 2010; 19(6):e49.

31. Aase I, Aase K, Dieckmann P. Teaching interprofessional teamwork in medical and nursing education in Norway: a content analysis. J Interprof Care. 2013;27(3):238-245.

32. Confederation of Postgraduate Medical Education Councils. Australian Curriculum Framework for Junior Doctors. Fitzroy, Australia: Confederation of Postgraduate Medical Education Councils; 2012. Available from: http://curriculum.cpmec.org.au/. Accessed: March 12, 2013.
Advances in Medical Education and Practice

\section{Publish your work in this journal}

Advances in Medical Education and Practice is an international, peerreviewed, open access journal that aims to present and publish research on Medical Education covering medical, dental, nursing and allied health care professional education. The journal covers undergraduate education, postgraduate training and continuing medical education

\section{Dovepress}

including emerging trends and innovative models linking education, research, and health care services. The manuscript management system is completely online and includes a very quick and fair peer-review system. Visit http://www.dovepress.com/testimonials.php to read real quotes from published authors. 